\title{
O ESPAÇO DA CULTURA Guia Cultural do Estado de São Paulo
}

\author{
Aurílio Sérgio Costa Caiado \\ Arquiteto, Professor na Universidade de Sorocaba e Analista da Fundação Seade
}

\begin{abstract}
Resumo: Este artigo é uma síntese das discussões teóricas da equipe que elaborou o Guia Cultural do Estado de São Paulo. Apresenta-se uma reflexão sobre o papel da cultura na constituição da identidade coletiva e das políticas culturais como instrumentos de desenvolvimento e os primeiros resultados a partir das informações coletadas pelo Guia Cultural, além de algumas considerações sobre a localização espacial dos equipamentos e atividades culturais.

Palavras-chave: cultura; espaço da cultura; política cultural; produção cultural.
\end{abstract}

A Fundação Seade realizou, durante quinze meses entre 1999 e 2000, um levantamento, em todos os municípios paulistas, dos equipamentos culturais $;{ }^{1}$ das atividades culturais ligadas às artes cênicas e visuais, música e literatura; ${ }^{2}$ do patrimônio cultural existente no município (entendido como o artesanato tradicional, festas, bens tombados, sítios históricos e arqueológi$\cos )$, bem como da estrutura administrativa e do aparato legal específico (lei municipal de proteção do patrimônio histórico, artístico, arquitetônico e arqueológico, lei municipal de incentivo à cultura, setor responsável pelo desenvolvimento de atividades culturais na prefeitura). Sem dúvida esse verdadeiro recenseamento do patrimônio cultural paulista é o trabalho mais amplo realizado no Estado e contém um grande conjunto de informações inéditas. Pela primeira vez foi organizado um levantamento de todos os bens tombados pelas três instâncias de poder em São Paulo. Até então, em que pesem a grande organização do Conselho de Defesa do Patrimônio Histórico, Arqueológico, Artístico e Turístico do Estado de São Paulo (Condephaat) e o consagrado trabalho realizado pelo Instituto do Patrimônio Histórico e Artístico Nacional (Iphan), não havia uma catalogação de todos os bens tombados pelos municípios. As leis municipais de incentivo à cultura, bem como aquelas destinadas à preservação do patrimônio histórico, artístico, arquitetônico ou arqueológico dos municípios, não tinham sido registradas em um único documento. Porém, o grande mérito do trabalho foi o desenvolvimento de uma metodologia de abordagem e compreensão da cultura e do processo cultural, que possibilitou a elaboração da pesquisa de campo, a organização e a publicação de seus resultados.

Em paralelo ao trabalho de campo, parte da equipe da Fundação Seade realizou um minucioso levantamento, em documentos oficiais, sobre a história da formação dos municípios, além da elaboração de mapas de localização de cada município e da organização de um rol de informações municipais atualizadas, existentes no banco de dados da Fundação Seade. Esse trabalho resultou no Guia Cultural do Estado de São Paulo, publicação com sete volumes e mais de três mil páginas, fruto de uma parceria entre a Fundação Seade e a Secretaria da Cultura do Estado de São Paulo, e que reúne um grande número de informações sobre a diversidade cultural paulista, contemplando desde as manifestações tradicionais até produções contemporâneas, além de uma minuciosa radiografia dos espaços físicos e grupos que se destinam ao ato de promover e fazer a cultura no Estado de São Paulo.

Trata-se de um produto que singulariza a identidade cultural dos diversos municípios paulistas ao levantar, organizar e qualificar informações sobre instituições, entidades, equipamentos, eventos, patrimônio cultural e práticas de gestão. Este trabalho exigiu o desenvolvimento de metodologia específica e trouxe, à equipe técnica da 
Fundação Seade, a possibilidade de pensar e propor novas abordagens no tratamento da informação em um assunto tão complexo e amplo como a Cultura. Além disso, foi necessário um entendimento, com algum grau de profundidade, das questões relativas à cultura no campo conceitual, que levasse em conta as recomendações dos organismos internacionais para a ação na área de políticas culturais.

Partiu-se do princípio de que tendo em vista o fato de os agentes culturais estarem sendo cada vez mais solicitados a promover a criação, a produção e a disseminação da cultura, bem como a regulamentação dos recursos humanos e materiais para o desenvolvimento das ações culturais, são fundamentais a sistematização do conhecimento e a organização das informações sobre o sistema cultural que, por outro lado, justamente por ser vivo, é complexo e mutável, intrinsecamente dinâmico e diverso.

Em um horizonte mais amplo, a cultura, presente na constituição da identidade coletiva, fundamental para a consolidação do Estado-Nação moderno, foi entendida como um fator estratégico para a garantia de um desenvolvimento sustentável. Por isso, em todas as etapas de elaboração do Guia Cultural, foram levadas em conta as recomendações da Unesco para elaboração de políticas culturais que devem ser, sobretudo, instrumentos de gestão das transformações e de garantia de identidades no âmbito de um mundo globalizado, favorecendo a criatividade, a participação e a expressão dos diversos grupos sociais.

Este artigo tem por objetivo apresentar uma síntese das discussões teóricas que permearam e balizaram a elaboração do Guia Cultural, bem como apresentar seus primeiros resultados consolidados.

\section{DA CULTURA DE MASSAS AO MERCADO CULTURAL}

O desafio colocado para a equipe técnica que desenvolveu o Guia Cultural foi o de definir uma abordagem que desse conta das especificidades da área cultural e, ao mesmo tempo, não a tratasse como uma ação setorial, com fim em si mesma, mas a incluísse como um dos componentes da diversidade regional e da singularidade de cada município (local). Para tanto, era fundamental ter um entendimento, mesmo que superficial, da importância da cultura como expressão do desenvolvimento social e seu papel na constituição da identidade coletiva.

Até a década de 70, o debate sobre cultura encontravase numa encruzilhada, na qual ela era vista como um ins- trumento de conscientização, ou "formação de uma vontade coletiva nacional popular" (Gransci, 1980) - a chamada cultura de massas - e, portanto, com importante papel no processo de transformação social, e, ao mesmo tempo, como um instrumento de reprodução dos valores ideológicos da classe dominante, ou "aparelho ideológico de Estado", segundo Althusser (1980).

Esse debate estava, sobretudo, presente na discussão acerca da constituição da identidade nacional e a formação do Estado-Nação.

A constituição dessa identidade coletiva -, que passou pela integração das diversas escalas espaço-temporais regionais, na qual a escola, a imprensa, a cultura e os meios de transportes e comunicações desempenharam um papel fundamental - na América Latina e no Brasil, em particular, foi problematizada por uma contradição acerca dos constrangimentos ao desenvolvimento.

Isso pode ser resumidamente explicado pelo fato de que, nos países industrializados (aqueles que participaram da primeira ou da segunda Revolução Industrial), a nação foi forjada sobre um discurso de modernidade, em que os valores modernos, industrializantes, foram contrapostos aos antigos, reformulando as condições existentes com mudanças estruturais. A industrialização, a urbanização e o surgimento de novas classes sociais implicaram uma rearticulação de todo o tecido social e, sem dúvida, essas transformações não se limitaram ao âmbito da infra-estrutura econômica. Trata-se "de uma condição, de uma nova cultura, com conceitos de espaço e de tempo particulares, que se atualiza em um modo de vida cujo substrato é a própria materialidade técnica" (Ortiz, 1995:19).

Assim, o mesmo "moinho satânico que triturou os homens transformando-os em massa" (Polanyi, 1980) foi peça fundamental na constituição do Estado-Nação e a emergência da modernidade ocorreu no mesmo período da constituição da nacionalidade, sendo parte constitutiva dela.

A questão é que essa materialidade técnica, base do progresso e do desenvolvimento, estava restrita a poucos territórios. Entretanto, as doutrinas imperialistas eram exibidas orgulhosamente ao mundo atrasado que, não podendo internalizar o progresso técnico e o desenvolvimento, passaram a buscar outros símbolos constitutivos da identidade nacional.

A metáfora hegeliana do mocho de Minerva, "que só levantaria vôo ao cair da tarde", não pode ser usada como justificativa para o descompasso entre a cultura e as transformações econômicas, como defendeu Weffort. Apontando como uma hipótese antiga e, em suas palavras, tal- 
vez a mais verdadeira, o "cultural lag", no qual "algum atraso da reflexão, assim como da cultura, em relação à economia e às mudanças de estrutura social ocorre sempre, em qualquer país", o autor afirma que "este atraso é tanto maior quanto mais rápida a transformação da economia e da sociedade" (Weffort, 2000:5). Entretanto, este é somente um subterfúgio do intelectual-ministro para justificar o descompasso entre a cultura e o desenvolvimento no Brasil.

Furtado, ao estudar o processo de constituição da cultura brasileira, afirma que a modernização dependente na qual o excedente gerado pelas vantagens comparativas estáticas criadas pela especialização na exportação de produtos primários e retido localmente modelou os padrões de comportamento através do estímulo à importação de manufaturas, cristalizando um certo padrão de divisão internacional do trabalho - fez com que a ruptura da síntese barroca conduzisse a padrões de comportamento imitativos, a um crescente bovarismo e não a um novo processo cultural criativo, diferentemente do ocorrido na Europa com a passagem da visão de mundo medieval para o humanismo, após a Revolução Industrial. Isso porque, segundo Furtado, "a eclosão do humanismo abre, na Europa, um processo criativo polifacético, que somente produzirá uma nova idéia global do homem com o romantismo. O dinamismo desse novo quadro cultural reflete o fundo móvel de uma sociedade competitiva, em que a criatividade tecnológica é um dos principais recursos de poder" (Furtado, 1984:21).

No Brasil, o fato de os portugueses, apesar de minoritários no solo brasileiro em comparação aos contingentes de negros escravos e de índios, terem mantido sob seu estrito controle as atividades comerciais durante mais de três séculos e se alimentarem de fontes culturais européias teve um peso avassalador na constituição de nossa cultura. O florescimento do barroco brasileiro constitui, nesse ponto de vista, uma síntese cultural do espírito europeu pré-renascimento, pois "o quadro histórico em que se forma o Brasil - articulação precoce em Portugal do Estado com a burguesia e total domínio da sociedade colonial pelo Estado e pela igreja - congela o processo cultural no universo europeu pré-humanismo" (Furtado, 1984:21).

Se analisado o processo de constituição da identidade nacional através das rupturas e continuidades, observase que no século XIX ocorreram duas grandes rupturas políticas: a independência nacional, em 1822; e a Proclamação da República, em 1889. Não obstante, aquele século deve ser caracterizado mais como uma fase de transição do que propriamente de ruptura. Isso porque a independência (desdobramento da coroa, segundo Furtado) preservou, inicialmente, a velha rede de entrelaçamentos econômicos, mas, ao constituir o Brasil em território independente, conduziu gradualmente também a uma reestruturação desse espaço de entrelaçamento. Por outro lado, a transição foi ratificada por uma alteração do regime - a Proclamação da República, em 1889. O regime de acumulação extensiva, que se tornara dominante, e a regulação compatível com ele formaram uma ordem relativamente estável, garantida pelo predomínio britânico, que mantinha o padrão cultural imitativo europeu e elitista.

Em todo o período, portanto, a constituição da identidade nacional e da cultura esteve borrada pelo descolamento entre a elite e o povo. Ao não privilegiar a internalização do progresso técnico, a elite apresentavase moderna através da imitação de comportamentos europeus, absorvendo padrões estéticos cosmopolitas e consumindo bens industrializados, propiciados pela exportação de produtos primários. O povo era reduzido a uma referência negativa, símbolo do atraso, e sua herança cultural e criatividade artística tinham significado nulo, por não ser européia.

Foi somente a partir do movimento modernista de 1922 que a cultura não-européia foi considerada constitutiva da cultura nacional. Entretanto, o debate sobre a modernização no mundo das artes observa um descompasso com o progresso das técnicas.

Ao afirmar que para ser moderno era preciso ser nacional, o movimento modernista de 1922 pretendia articular nossas artes plásticas à técnica e ao formalismo internacionais e, com isso, superar a defasagem estética. Retomar o ideal de modernidade, naquele momento, foi a maneira encontrada para ajustar nosso relógio ao tempo das exigências universais. Entretanto, o modernismo, ao se revelar nacional "arrastava uma ambigüidade intrínseca, pois a renovação estética se fez, na América Latina, sem modernização alguma. (...) Para eles o moderno era mais um projeto, algo a ser realizado no futuro, que propriamente a tradução da realidade atual. Assim, a modernidade ausente reencontra, neste ponto, o Estado-Nação inacabado" (Ortiz, 1995:19).

$\mathrm{O}$ ano de 1930 marcou uma nova ruptura com a instituição de um ordenamento que vinha sendo gestado durante toda a década de 20 e cuja direção tornou-se irreversível. Desse modo, iniciou-se nos anos 30, com a crise da economia agrário-exportadora, uma nova fase 
centrada no Estado Nacional - que se consolidou após a Segunda Guerra mundial -, baseada em uma industrialização tardia, apoiada no mercado interno e sustentada pela urbanização crescente.

Entretanto, como os signos da modernidade são tênues, a nação só conseguiu expressar-se através de símbolos ligados à cultura popular. Desse modo, na década de 30, o Governo Vargas, apesar de ter se colocado como promotor do desenvolvimento e da transformação social, escolheu para representá-lo símbolos que pertencem ao domínio da tradição.

É importante destacar que, graças ao desprezo das elites pela cultura popular, houve possibilidade de transmissão e consolidação das nossas raízes não-européias nos períodos colonial, imperial e na primeira república, o que permitiu a expansão da sua força criativa sem a inibição da cultura dominante. Por esse motivo, ao buscar símbolos nacionais, na ausência de símbolos modernos vinculados ao desenvolvimento industrial, o Governo Vargas inventou como símbolos da identidade nacional o carnaval, o samba e o futebol (Ortiz, 1995).

Como não há separação entre realidade e representação simbólica, fica a dúvida se esses símbolos foram apropriados de forma alegorizada pelo imaginário nacional e, dessa forma, manteve-se a distância entre a elite e o povo, ou se são exatamente a síntese do ambiente simbólico, expressão viva das contradições e distâncias entre os distintos anseios de classes e projetos de nação.

A continuidade do processo de consolidação do quadro cultural nacional seguiu por curto período democrático (1945-64) e longos períodos autoritários (1937-45 e 1964-84), mas sempre baseado na dicotomia elite-povo. Esta continuidade foi permanentemente bombardeada pela ascensão do padrão do consumo ditado pela economia norte-americana, que impulsionou uma cultura de massas dotada de meios extraordinários de difusão, que desestabilizavam o quadro cultural nacional, incutindo novos valores.

As características marcantes desse período foram, por um lado, a busca de uma identidade nacional e a forte presença do Estado empreendedor e industrializante e, por outro, o surgimento de uma classe média urbana, de importância econômica crescente, ávida por adquirir novos (modernos) símbolos que expressassem seu rompimento com o atraso rural.

O processo acelerado de urbanização e industrialização permitiu uma apropriação de valores modernos, reduzindo a distância entre desenvolvimento e cultura.
Entretanto, a classe média brasileira, formada no quadro de modernização dependente, mediatizada por uma industrialização que seguiu as linhas de substituição de importações, tem grande parte de seus elementos demasiadamente próximos do povo para ignorar sua significação cultural. A ênfase na identidade nacional proporciona argumentos sólidos contra a exploração estrangeira. A questão nacional estimula a criatividade cultural, que se nutre da problemática da nacionalidade para renovar e expandir o universo estético (Ortiz, 1995).

Além disso, o caráter de massa da cultura da classe média faz com que suas relações com o povo não sejam de exclusão, mas sim de envolvimento e penetração. Assim, embora alegorizada pela ascensão da cultura de classe média, a cultura de massa, baseada nos valores populares e em sua força criativa, mesmo bombardeada pela introdução de padrões exógenos de comportamento e consumo, está amalgamada no projeto de constituição de uma identidade nacional.

É importante destacar que "a modernidade se encontra articulada à racionalização da sociedade, em seus diversos níveis, econômico e cultural. Expressa uma forma de organização social enquanto cultura, isto é, um sistema simbólico específico. Espaço e tempo, por exemplo, são categorias que devem ser reelaboradas em cada contexto, pois o universo cotidiano dos homens está pontuado pela racionalidade do industrialismo e da técnica" (Ortiz, 1995:20).

Assim, a consolidação do sistema de produção e reprodução do capital em escala planetária, chamado mundialização do capital ou globalização da economia, traz consigo um movimento de mundialização da cultura, modificando nossa situação histórica. ${ }^{3}$

A globalização dos mercados não está restrita ao nível econômico, pois, além de alterar a ética do trabalho (Mattoso, 1994), pressupõe a difusão de novos valores e um processo de construção da "sociedade global" que, segundo Ianni (1992), emerge como um produto inevitável da instantaneidade da informação e, como justifica Harvey (1992), da compressão do espaço pelo tempo. Isso graças à velocidade das informações difundidas pelos modernos sistemas de comunicações, que fazem com que uma grande variedade de informações chegue instantaneamente a milhões de residências em diversos países.

Essas informações trazem consigo normas e valores que se internacionalizam, possibilitando a diferentes povos a redefinição de padrões e aspirações de comportamento na construção de um novo imaginário sobre o seu e os outros países. 
Esta nova rodada de compressão do espaço pelo tempo significa, para alguns autores, "o fim do ciclo que se abriu no século XVI" (Furtado, 1984).

O surgimento de um novo sistema eletrônico de comunicação - caracterizado pelo seu alcance global, integração de todos os meios de comunicação e interatividade potencial - está mudando e mudará para sempre nossa cultura, com o surgimento de uma cultura da virtualidade real (Castells, 1999). A constituição dessa "aldeia global" (McLuhan e Powers, 1989), composta por uma maioria silenciosa (Baudrillard, 1985), tem seus signos baseados na virtualidade real, que vem a ser um sistema em que a própria realidade (ou seja, a experiência simbólica/material das pessoas) é "inteiramente captada, totalmente imersa em uma composição de imagens virtuais no mundo do fazde-conta, no qual as aparências não apenas se encontram na tela comunicadora da experiência, mas se transformam na experiência" (Castells, 1999:395).

Por outro lado, esse novo sistema de comunicação transforma radicalmente as dimensões fundamentais da vida humana - o espaço e o tempo - e as localidades (regiões e até países) perdem seu sentido cultural, histórico e geográfico e reintegram-se em redes funcionais ou em colagens de imagens, ocasionando um espaço de fluxos que substitui o espaço de lugares.

"O tempo é apagado no novo sistema de comunicação já que passado, presente e futuro podem ser programados para interagir entre si na mesma mensagem. O espaço de fluxos e o tempo intemporal são as bases principais de uma nova cultura, que transcende e inclui a diversidade dos sistemas de representação historicamente transmitidos: a cultura da virtualidade real, onde o faz-de-conta vai se tornando realidade" (Castells, 1999:397-98).

Nesse sentido, é fundamental que haja reconhecimento da diversidade cultural, a partir das peculiaridades de cada local, pois assim será fortalecida a identidade entre o indivíduo e seu grupo e entre este, o meio ambiente e a sociedade. Só através do fortalecimento desses vínculos serão mantidas as verdadeiras raízes culturais e reduzida a pressão da "cultura mundializada".

Nessa sociedade em rede, todos o povos lutam para ter acesso ao patrimônio cultural comum da humanidade, que se enriquece, permanentemente, mas poucos continuarão a contribuir para esse enriquecimento e, aos outros, restará o papel passivo de simples consumidores de bens culturais adquiridos no mercado. Assim, a cultura é transformada em objeto de consumo e a produção cultural é cada vez mais desterritorializada e transformada em mercado cultural.
A negação da existência desse mercado seria, para a equipe que elaborou o Guia Cultural do Estado de São Paulo, uma ingenuidade e significaria a perda de oportunidade de levantar, registrar e divulgar as expressões reais da cultura no Estado. Nesse momento, em que a ação avassaladora dos sistemas de comunicações destroem e reconstroem valores e símbolos, é fundamental trabalhar de forma a integrar todas as mensagens do padrão cognitivo, quer seja no intuito de preservá-las, quer seja para divulgá-las, possibilitando sua inserção nesse mercado e propiciando a formulação de políticas culturais que contribuam para o desenvolvimento.

\section{PRIMEIROS RESULTADOS EXTRAIIDOS DO GUIA CULTURAL}

De uma forma sintética, serão apresentados os principais resultados da pesquisa que originou o Guia Cultural. Na publicação original, as informações aqui apresentadas de forma agregada estão organizadas como um cadastro, composto de um rol amplo de dados, tais como endereço, entidade mantenedora, capacidade e/ou acervo, etc.

\section{Equipamentos Culturais}

Segundo as informações coletadas, existem no Estado de São Paulo 4.108 espaços destinados a atividades desenvolvidas nas diferentes áreas culturais e que são de utilização pública permanente (Tabela 1).

É interessante observar que a localização dos equipamentos, no Estado, não é proporcional à distribuição da população. Aqueles utilizados pelo mercado cultural (cinemas, teatros, cineteatros e centros culturais) têm uma maior concentração na Região Metropolitana de São Paulo, enquanto os outros (de uso livre e, via-de-regra, sem cobrança de ingresso) se localizam mais no interior.

Entre os equipamentos existentes no Estado, as bibliotecas aparecem em maior número (1.199), representando 29,2\% do total. ${ }^{4}$ É importante registrar que 119 municípios paulistas $(18,5 \%)$ não possuem nenhuma biblioteca de uso público. As prefeituras são responsáveis pela manutenção de mais de $70 \%$ das bibliotecas, seguidas pelo Governo do Estado (17,9\%), por empresas privadas (7,0\%) e por outras entidades (menos de $5 \%$ ).

Os auditórios e os coretos vêm em segundo lugar em termos de quantidade, com participações bastante semelhantes: $14,1 \%$ e $13,8 \%$, respectivamente e, do total de equipamentos existentes nos municípios paulistas. Entre- 
TABELA 1

Equipamentos Culturais, por Tipos

Regiões Metropolitanas, Regiões Administrativas e o Município de São Paulo - 2000

\begin{tabular}{|c|c|c|c|c|c|c|c|c|c|c|c|c|c|}
\hline Regiões Administrativas & $\begin{array}{l}\text { Anfi- } \\
\text { teatros }\end{array}$ & Arquivos & Auditórios & $\begin{array}{l}\text { Biblio- } \\
\text { tecas }\end{array}$ & $\begin{array}{l}\text { Centros } \\
\text { Culturais } \\
\text { e/ou Casas } \\
\text { de Cultura }\end{array}$ & $\begin{array}{l}\text { Salas de } \\
\text { Cinema } \\
(1)\end{array}$ & $\begin{array}{l}\text { Cine- } \\
\text { teatros }\end{array}$ & $\begin{array}{l}\text { Conchas } \\
\text { Acústicas }\end{array}$ & Coretos & Museus & $\begin{array}{c}\text { Teatros } \\
\text { (2) }\end{array}$ & $\begin{array}{l}\text { Outros } \\
\text { Espaços } \\
\text { Culturais }\end{array}$ & Total \\
\hline ESTADO DE SÃO PAULO & (3) 48 & 147 & (3) 466 & 1.199 & 368 & 443 & (3) 55 & (3) 74 & (3) 455 & 331 & 252 & 270 & (4) 4.108 \\
\hline \multicolumn{14}{|l|}{ Região Metropolitana } \\
\hline de São Paulo & (3) 3 & 19 & (3) 35 & 383 & 100 & 273 & (3) 7 & (3) 9 & (3) 31 & 94 & 121 & 40 & (4) 1.115 \\
\hline Município de São Paulo & (5) $\ldots$ & 12 & (5) $\ldots$ & 299 & 39 & 205 & (5) $\ldots$ & (5) $\ldots$ & (5) $\ldots$ & 74 & 100 & 22 & (5) $\ldots$ \\
\hline RA de Registro & - & 2 & 6 & 15 & 5 & 1 & - & 2 & 7 & 5 & - & - & 43 \\
\hline \multicolumn{14}{|l|}{ Região Metropolitana } \\
\hline da Baixada Santista & 2 & 4 & 5 & 33 & 9 & 10 & 1 & 1 & 6 & 10 & 8 & 6 & 95 \\
\hline RA de São José dos Campos & 2 & 15 & 37 & 47 & 26 & 20 & 5 & 3 & 26 & 25 & 8 & 6 & 220 \\
\hline RA de Sorocaba & 4 & 16 & 62 & 125 & 37 & 21 & 7 & 14 & 50 & 34 & 16 & 29 & 415 \\
\hline RA de Campinas & 14 & 29 & 116 & 154 & 61 & 52 & 10 & 18 & 97 & 60 & 38 & 62 & 711 \\
\hline RA de Ribeirão Preto & 3 & 4 & 29 & 37 & 12 & 22 & 2 & 3 & 35 & 16 & 11 & 14 & 188 \\
\hline RA de Bauru & 2 & 6 & 33 & 49 & 15 & 6 & 4 & 5 & 40 & 11 & 10 & 42 & 223 \\
\hline RA de São José do Rio Preto & 5 & 24 & 30 & 86 & 27 & 9 & 3 & 3 & 40 & 17 & 11 & 11 & 267 \\
\hline RA de Araçatuba & - & 2 & 10 & 33 & 15 & 5 & 1 & 1 & 14 & 7 & 3 & 3 & 94 \\
\hline RA de Presidente Prudente & 8 & 5 & 35 & 91 & 14 & 5 & 0 & 2 & 25 & 13 & 7 & 19 & 224 \\
\hline RA de Marília & 2 & 6 & 22 & 62 & 13 & 6 & 3 & 6 & 23 & 14 & 4 & 5 & 166 \\
\hline RA Central & 1 & 10 & 26 & 39 & 14 & 6 & 4 & 2 & 29 & 10 & 6 & 10 & 157 \\
\hline RA de Barretos & 1 & 2 & 11 & 21 & 8 & 3 & 2 & 3 & 15 & 8 & 3 & 5 & 82 \\
\hline RA de Franca & 1 & 3 & 9 & 24 & 12 & 3 & 6 & 2 & 17 & 7 & 6 & 18 & 108 \\
\hline
\end{tabular}

Fonte: Fundação Seade; Secretaria de Estado da Cultura. Guia Cultural do Estado de São Paulo, 2001.

(1) Foram consideradas as salas de projeção.

(2) Foram consideradas as salas de espetáculo.

(3) Não incluem o Município de São Paulo.

(4) Não incluem os anfiteatros, os auditórios, as conchas acústicas e os coretos do Município de São Paulo.

(5) Dados não disponiveis.

tanto, sua distribuição espacial é bem distinta, pois, enquanto os coretos estão presentes em $53,8 \%$ dos municípios, os auditórios aparecem em apenas $27,6 \%$.

Cinemas $(10,8 \%)$, centros culturais $(9,0 \%)$, museus $(8,0 \%)$ e teatros e cineteatros $(7,5 \%)$ são os outros equipamentos existentes em maior número no Estado. Os museus, no entanto, estão mais bem distribuídos entre os municípios e os cinemas apresentam maior concentração: $26,9 \%$ dos municípios possuem museus e apenas $11,9 \%$ têm cinemas.

A maior parte dos museus $(73,6 \%)$ é mantida pelas prefeituras, $8,1 \%$ pelo Governo Estadual e o restante se divide, principalmente, entre empresas privadas, fundações ou institutos privados, parcerias entre instâncias governamentais e entidades religiosas.
A iniciativa privada é mantenedora da maioria dos cinemas $(94,5 \%)$, sendo que a pequena parcela restante está distribuída entre prefeituras, clubes e associações e entidades religiosas.

Os centros culturais e/ou casas de cultura estão presentes em $37,7 \%$ dos municípios paulistas e as prefeituras são responsáveis pela manutenção de $60,5 \%$ deles.

Os teatros encontram-se distribuídos em $14,5 \%$ dos municípios, sendo que mais da metade $(56,2 \%)$ é mantida pelas prefeituras, $11,9 \%$ por empresas privadas e os demais por fundações ou institutos privados, clubes e associações, Governo do Estado e outros.

Os arquivos são, em sua maioria, mantidos pelas prefeituras e estão presentes em cerca de $19 \%$ dos municípios pesquisados. 
Observa-se que, no conjunto, as prefeituras são as principais proprietárias de espaços utilizados permanentemente para atividades, eventos ou ações culturais, além de atuarem na área de empreendimentos culturais, através de incentivos fiscais para sua realização.

O sucesso da implementação e, sobretudo, do financiamento das ações culturais está cada vez mais ligado à articulação de parcerias responsáveis entre o Estado, a iniciativa privada, as organizações não-governamentais e as comunidades.

Na última década, o governo, nas suas diversas instâncias - federal, estadual e municipal -, tem promulgado várias leis de incentivo à cultura. Trata-se de dispositivos legais que permitem aos produtores e às instituições usufruírem diretamente do benefício de recursos públicos para a realização de projetos culturais.

A Lei Rouanet (Lei Federal no 8.313/91), que substituiu a Lei Sarney (Lei Federal $n^{\circ} 7.505 / 86$ ), permite a aplicação em projetos culturais selecionados de recursos oriundos da renúncia fiscal, Imposto de Renda de pessoas físicas e jurídicas. A Lei de Incentivo à Cultura do Governo do Estado de São Paulo (Lei Estadual no 8.819/94) seleciona projetos inscritos que atendam a edital, distribuindo diretamente recursos mediante contrapartida. A lei municipal da cidade de São Paulo - Lei Mendonça (Lei Municipal $n^{\circ} 10.923 / 90$ ) - incentiva projetos inscritos e aprovados em forma de isenção de impostos (IPTU e ISS) concedida aos investidores.

No Estado de São Paulo, outros 56 municípios, além da capital, possuem lei municipal de incentivo à cultura. Apenas um município conta com uma lei promulgada em 1980 e dois com leis promulgadas em 1989. Nos demais, as leis foram elaboradas na década de 90 , com maior concentração no triênio 1992-94 (22 municípios). As datas confirmam um certo acompanhamento às iniciativas federal e estadual, o que tenderia a crescer à medida que os municípios fossem se inteirando do funcionamento das leis já em vigor e participando de iniciativas patrocinadas por elas, reconhecendo tratar-se de uma alternativa para financiar a promoção da cultura e a preservação do patrimônio.

\section{Atividades Culturais}

Muitos outros temas levantados pelo Guia Cultural poderiam ser aqui apresentados, entretanto, em função dos objetivos deste artigo, será destacado sinteticamente, o que mais chama atenção sobre as atividades culturais.
Artes Cênicas - Foram levantados 854 grupos de artes cênicas presentes em $39,3 \%$ dos municípios paulistas, exceto a capital. ${ }^{5}$ A maioria é mantida por empresas privadas ou grupos autônomos: $30,3 \%$ e $28,8 \%$, respectivamente. As prefeituras mantêm $17,8 \%$ e os clubes e associações, $14,9 \%$.

Os 388 cursos de artes cênicas registrados concentramse em 177 municípios e, em sua maioria (52,3\%), são mantidos por empresas privadas. As prefeituras respondem por $30,1 \%$ dos cursos oferecidos.

Foram identificados 346 eventos de artes cênicas em 176 municípios $(27,3 \%)$, sendo mais da metade realizada pelas prefeituras $(57,5 \%)$.

Artes Visuais - São realizados, fora do Município de São Paulo, 321 eventos de artes visuais com calendário fixo em 173 municípios, $77,0 \%$ dos quais promovidos pelas prefeituras.

Os grupos ou associações de artes visuais estão presentes em 99 municípios, perfazendo um total de 176 grupos, mantidos, em sua maior parte, pela esfera privada $(57,4 \%)$, seguida por entidades pertencentes ao chamado "terceiro setor" (19,3\%), como sindicatos, fundações, clubes, associações e outras. Na esfera governamental, apenas as prefeituras sobressaem na promoção desses grupos ou associações (19,9\%), inexistindo a atuação de órgãos estaduais ou federais.

A participação de instâncias governamentais nos cursos de artes visuais, entretanto, é mais expressiva, com $38,5 \%$, e as prefeituras representam $35,9 \%$ desse total. A iniciativa privada, por intermédio de empresas ou grupos autônomos, responde por $54,2 \%$ dos cursos existentes.

Literatura - São realizados, anualmente, 170 eventos literários com calendário fixo, em 116 municípios do Estado de São Paulo, excluindo-se os que ocorrem na capital. Os 88 grupos ou associações literárias existentes fora do $\mathrm{Mu}-$ nicípio de São Paulo estão distribuídos em 58 municípios.

A prefeitura é a principal entidade promotora dos eventos literários, respondendo por $60,6 \%$ do total, seguida pelas parcerias entre instâncias governamentais, com 13,5\%.

Os grupos ou associações literárias são mantidos, principalmente, por clubes e associações $(50,0 \%)$, presentes em 30 municípios vindo em segundo lugar as prefeituras $(17,0 \%)$.

Música - Existem, fora da capital, 459 eventos musicais com calendário fixo, realizados em 231 municípios do 
MAPA 1

Equipamentos Culturais, por Tipo, segundo Renda Média Familiar

Município de São Paulo - 2000

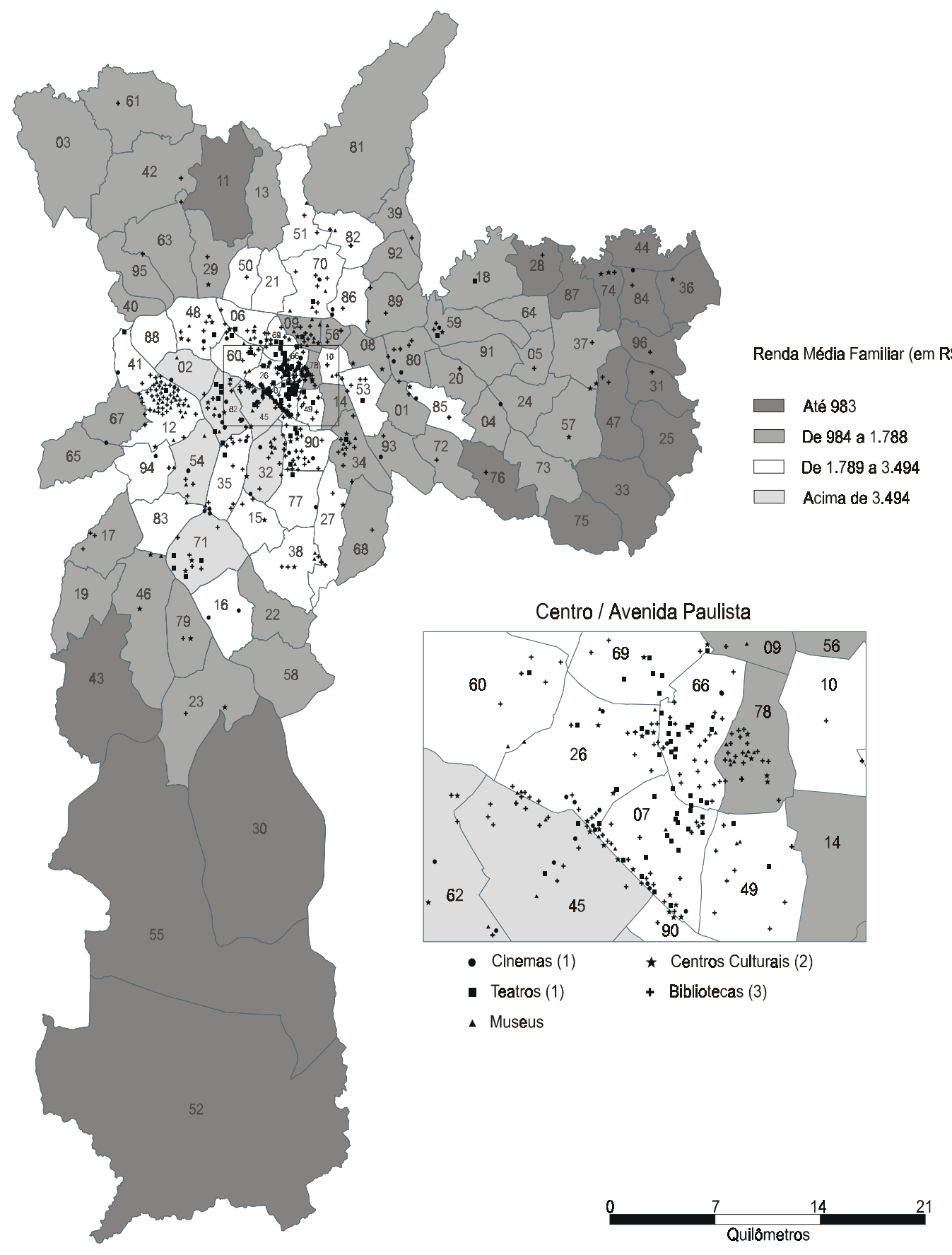

Fonte: Fundação Seade; Secretaria de Estado da Cultura.

(1) Podem ter mais de uma sala, como aquelas localizadas em shoppings.

(2) Inclui casas de cultura, espaços culturais e oficinas culturais.

(3) Inclui bibliotecas: infantis, privadas, públicas, universitárias e de instituições públicas. 
MAPA 2

Equipamentos Culturais, por Tipo, segundo Distribuição Populacional

Município de São Paulo - 2000

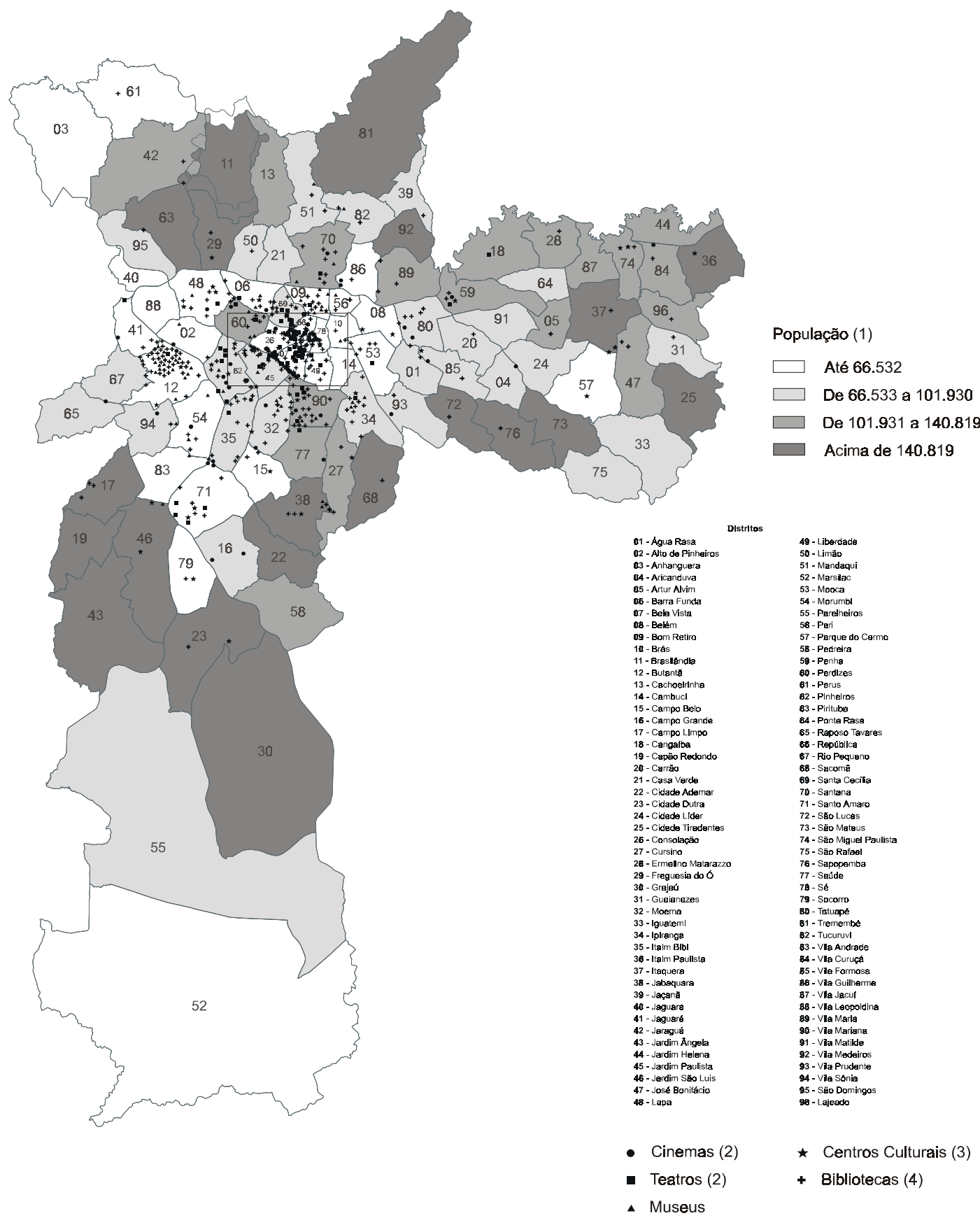

Fonte: Fundação Seade; Secretaria de Estado da Cultura.

(1) Os dados populacionais são de 1996.

(2) Podem ter mais de uma sala, como aquelas localizadas em shoppings.

(3) Inclui casas de cultura, espaços culturais e oficinas culturais.

(4) Inclui bibliotecas: infantis, privadas, públicas, universitárias e de instituições públicas. 
Estado de São Paulo. A maior parte $(72,6 \%)$ é promovida pelas prefeituras e os demais têm como promotores empresas privadas $(7,4 \%)$ e clubes e associações $(3,9 \%)$.

Foram registrados, também, 1.663 grupos ou associações musicais presentes em 427 municípios (66,3\% dos pesquisados), sendo que a instituição mantenedora com maior presença corresponde às prefeituras $(30,2 \%)$. Significativos também são os grupos autônomos $(29,6 \%)$ e os mantidos por empresas privadas $(15,5 \%)$.

São 544 os cursos ou escolas de música legalmente constituídos e em atividades há três anos ou mais, no Estado de São Paulo, fora a capital. Estes estão instalados em 278 municípios e são, na sua maioria, privados (254 escolas) ou mantidos pelas prefeituras (175 cursos em 147 municípios).

\section{Meios de Comunicação}

Existem 563 rádios no Estado, fora do Município de São Paulo, localizadas em 287 municípios. Destas, 327 transmitem em FM, 59 em AM e FM e 177 em AM. É importante destacar que, em mais da metade dos municípios paulistas (357) não existe nenhuma emissora de rádio.

Os órgãos de imprensa escrita são em maior número (789 jornais ou revistas) e mais disseminados pelo interior (347 municípios) do que as emissoras de rádio. Um total de 706 jornais possuem circulação diária ou semanal, instalados em 324 municípios. Aqueles que circulam com periodicidade quinzenal ou mensal somam 47 jornais, em 34 municípios, e há 36 revistas editadas em 27 cidades. Pode-se deduzir, com as informações apresentadas, que em 297 municípios paulistas não circula nenhum veículo de comunicação escrita produzido localmente.

\section{Audiovisual}

No setor de audiovisual a pesquisa privilegiou o levantamento sobre a área de cinema. $\mathrm{O}$ objetivo foi catalogar todas as atividades desenvolvidas nos municípios.

Existem no Estado de São Paulo 27 eventos ligados ao cinema, que ocorrem em 19 municípios, exceto a capital. A maioria $(51,8 \%)$ é promovida pelas prefeituras e os demais são de responsabilidade de clubes e associações, fundações ou institutos privados, cada um com $18,5 \%$ do total de eventos.

São 16 os grupos, associações ou cursos de cinema existentes fora do município de São Paulo, distribuídos em 14 cidades do Estado. As prefeituras e as empresas privadas configuram-se como principais entidades mantenedoras $(25,0 \%$ cada uma), seguidas por clubes e associações $(18,7 \%)$ e fundações ou institutos privados $(12,5 \%)$.

\section{A ESPACIALIZAÇÃO DOS EQUIPAMENTOS E ATIVIDADES CULTURAIS}

Como síntese geral das observações destacadas do Guia Cultural, pode-se dizer que o grande mecenas no Estado de São Paulo é o poder público, com destaque para as prefeituras. Esta é uma observação muito interessante, pois as prefeituras, por estarem mais próximas da população, têm mais condições de atuar pela preservação dos reais valores da comunidade, e, com isso, reduzir o impacto avassalador (e pasteurizador) dos meios de comunicação de massa.

A questão subjacente é: quem se apropria, ou quais setores sociais mais se beneficiam da ação do Estado na cultura? Para essa resposta, talvez o Guia Cultural não seja uma boa fonte, mas é possível tecer algumas considerações através das informações coletadas.

Os menores municípios, na escala populacional, e os mais podres, quanto à geração de valor, são os de maior precariedade quanto à existência de equipamentos e ações culturais. É importante lembrar que esse conjunto e municípios congrega, proporcionalmente, uma maior parcela de população de baixa renda que a média, pois "a concentração relativa de famílias das classes D e E é inversamente proporcional ao porte do município ou aglomeração." (Caiado, 1997:127). Entretanto, só por essa informação não se pode afirmar que o acesso a equipamentos, atividades e eventos culturais privilegia as camadas de população de melhor renda, em detrimento daquelas de baixa renda.

Procurou-se então observar, no município de São Paulo, que congrega cerca de $25 \%$ da população paulista, onde estão localizados os principais equipamentos culturais.

É óbvio que não se pode esquecer da força centrípeta exercida pelo centro das cidades na determinação da localização dos equipamentos de uso coletivo, pois "não se coloca um teatro de ópera, uma loja de departamentos ou uma universidade em qualquer parte. O sucesso de certas aglomerações (os centros) é o verso de uma medalha cujo reverso necessário é a mediocridade de sua periferia. Mediocridade que é só relativa: até o mais humilde lugarejo, um lugar urbano, é sempre o centro de uma periferia (...) uma rede mais fina" (Benko e Lipietz, 1992:18). 
Entretanto, essa variável (centralidade) é tão maior no processo de decisão locacional de um equipamento cultural quanto maior for sua focalização no mercado cultu$\mathrm{ral}$, ou quanto menor for a preocupação em atender efetivamente à população (de baixa renda, principalmente).

Ora, se todo artista tem que ir aonde o povo está, os equipamentos culturais também deveriam ser localizados onde há maior concentração da população, independentemente de sua capacidade de consumo, determinada pela renda.

No Município de São Paulo, há uma grande concentração dos equipamentos culturais no centro da cidade e nos distritos onde reside a população de alta e média rendas (com recursos suficientes para alimentar o mercado cultural). Os distritos onde a maioria dos residentes é de baixa renda são desprovidos de equipamentos culturais, ou os têm em proporção muito reduzida. Assim, pode-se afirmar que os equipamentos culturais existentes na cidade de São Paulo não se localizam nos locais de residência da maioria da população (Mapas 1 e 2).

A conclusão é que há uma forte seletividade na localização dos equipamentos culturais e, em que pese o importante papel desempenhado pelo poder público como o principal mecenas no Estado, as camadas de mais baixa renda estão mais expostas às pressões exógenas exercidas pela mídia, tanto regionalmente (nos pequenos municípios), quanto no interior do tecido urbano (periferia).

\section{NOTAS}

E-mail do autor: ascaiado@seade.gov.br

Este artigo é fruto da reflexão conjunta da equipe que elaborou o Guia Cultural do Estado de São Paulo e contou com a colaboração de Cecilia Rodrigues dos Santos, Luís Carlos Barato Brás, Luís Augusto de M. Guisard e Antonio Carlos G. Gonçalves.

1. Foram considerados os seguintes equipamentos: anfiteatros, arquivos, auditórios, bibliotecas, casas da cultura, centros culturais, cinemas, cineteatros, conchas acústicas, coretos, museus, teatros, outros espaços culturais.

2. As atividades culturais foram agrupadas em artes cênicas (circo, dança, ópera, teatro), artes visuais (artes gráficas, desenho, design de objetos, escultura, fotografia, gravura, pintura), música (banda/fanfarra, canto coral, conjunto ou grupo instrumental e/ou vocal, orquestra) e literatura (academia de letras, clube de leitura, concursos literários, eventos literários, feira de livros, festival de poesia). Nos quatro casos foram levantadas informações sobre cursos, grupos, associações e eventos realizados.

3. A globalização da economia pode ser entendida como um estágio mais avançado do processo histórico de internacionalização do capital. Tem suas bases assentadas sobre um período de aceleração intensa e desigual da mudança tecnológica entre as economias centrais; de reorganização dos padrões de gestão e de produção, de forma a combinar os movimentos de globalização e regionalização; de difusão desigual da revolução tecnológica, reiterando os desequilíbrios comerciais e de balanço de pagamentos; de significativo aumento do número de oligopólios globais; de intensos fluxos de capitais e da interpenetração patrimonial dentro da tríade na ausência de um padrão monetário mundial.
4. É importante observar que a exigência para incluir um equipamento no Guia Cultural foi sua utilização pública e permanente, independentemente se a propriedade, ou o controle, fosse público ou privado. Por esse motivo, as bibliotecas escolares não abertas ao público externo não foram incluídas.

5. Esta questão não foi pesquisada no Município de São Paulo.

\section{REFERÊNCIAS BIBLIOGRÁFICAS}

ALTHUSSER, L. Ideologia e aparelhos ideológicos do Estado. Lisboa, Editorial Presença, 1980.

BAUDRILLARD, J. À sombra das maiorias silenciosas: o fim do social e o surgimento das massas. São Paulo, Editora Brasiliense, 1985.

BENKO, G. e LIPIETZ, A. Le nouveau débat régional: posicions. In: BENKO, G. e LIPIETZ, A. (orgs.). Les régions qui gagnent. districts et réseaux: les nouveaux paradigmes de la géographie économique. Paris, Presses Universitaires de France, 1992, p.13-32.

CAIADO, A.S. "Metrópoles, cidades médias e pequenos municípios paulistas: estudo comparado da qualidade de vida e dinâmica socioespacial". In: PATARRA, N.; BAENINGER, R.; BOGUS, L. e JANUZZI, P. (orgs.). $M i$ grações, condições de vida e dinâmica urbana: São Paulo 1980-1993. Campinas, Unicamp/Instituto de Economia, 1997, p.115-152.

CASTELlS, M. Sociedade em rede. Rio de Janeiro, Paz e Terra, 1999.

DAVIS, M. Cidade de quartzo. Escavando o futuro em Los Angeles. São Paulo, Editora Página Aberta, 1993.

FUNDAÇÃO SEADE; SECRETARIA DE ESTADO DA CULTURA. Guia Cultural do Estado de São Paulo. São Paulo, Fundação Seade, 2001.

FURTADO, C. Cultura e desenvolvimento em época de crise. Rio de Janeiro, Paz e Terra, 1984.

GRAMSCI, A. Maquiavel, a política e o Estado moderno. 4a ed. Rio de Janeiro, Civilização Brasileira, 1980.

HARVEY, D. A condição pós-moderna. São Paulo, Edições Loyola, 1992.

HUGHES, R. Barcelona. São Paulo, Companhia das Letras, 1995.

IANNI, O. A sociedade global. Rio de Janeiro, Civilização Brasileira, 1992.

LASCH, C. A cultura do narciso. A vida americana numa era de esperanças em declínio. Rio de Janeiro, Imago, 1983.

MATTOSO, J.E. "O novo e inseguro mundo do trabalho nos países desenvolvidos". O mundo do trabalho: crise e mudança no final do século. São Paulo, Editora Página Aberta Ltda., 1994, p. 521-562.

McLUHAN, M. Understanding media: the extencion of man. Nova York, McGraw Hill, 1964.

McLUHAN, M. e POWERS, B.R. The global village: transformation in word life and media in the $21^{\text {st }}$ century. Nova York, Oxford University Press, 1989.

NICOL, L. "Communications tecnology: economic and spatial impacts". In: CASTELLS, M. (org.). High tecnology, space, and society. Londres, Sage Publications, v.28, Urban Affairs Annual Reviews, 1988, p.191-209.

OFFE, C. Problemas estruturais do Estado capitalista. Rio de janeiro, Edições Tempo Brasileiro, 1984.

ORTIZ, R. Cultura e modernidade. São Paulo, Editora Brasiliense, 1991. Mundialização da cultura. São Paulo, Editora Brasiliense, 1994. "Cultura, modernidad e identidades". Nueva Sociedad. Caracas, Editorial Texto, n.137, mayo-junio 1995, p.17-23.

POLANYI, K. A grande transformação. Rio de Janeiro, Editora Campus, 1980.

SASSEN, S. The mobility of labor and capital. Cambridge, Cambridge Universite Press, 1988.

WEFFORT, F. “A cultura e as revoluções da modernização.” Cadernos do Nosso Tempo. Brasília, Ministério da Cultura, 2000. 